\title{
Experimental Study on Influence of Slurry Concentration on Gel Time of Double Liquid Grouting Material
}

\author{
Yanfang $\mathrm{Li}^{\mathrm{a}}$, Hongliang Huang ${ }^{\mathrm{b}}$ and Sulan $\mathrm{Li}^{\mathrm{c}}$ \\ Hebei University of Architecture, Zhangjiakou 075000, China

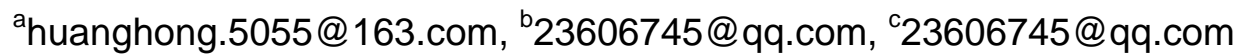

Keywords: Concentration, Double liquid, Grouting material, Gel time, Experimental research

\begin{abstract}
The selection of cement slurry with different consistency and different concentrations of Sodium silicate, design and test research on the mixture ratio of cement-Sodium silicate grouting material, $4 \mathrm{~W} / \mathrm{C}$ and $4{ }^{0}$ Bé co design 16 groups of proportion, through the collation and analysis of experimental data, obtained the relationship of mud-water slurry concentration influencing on cement-Sodium silicate double liquid grouting material's gel time.
\end{abstract}

\section{Introduction}

With the progress of the society, the development of science and the wide spread and application of grouting equipment and technology, in foundation reinforcement, the formulation composition, construction technology and using performance of grouting material have been greatly developed and improved. Cement-Sodium silicate grouting material in this research (i.e. C-S double liquid grouting material) is one of the advanced grouting materials commonly used in building foundation reinforcement engineering. It uses cement, Sodium silicate as the main agent (if necessary, adding additives), will both proportionally and respectively pump mixed, then injection of grouting process of formation.

\section{Test Materials and Equipment}

Raw Materials. The main test parameters of raw materials used in this project and its basic properties(Table 1).

Table 1 Raw materials

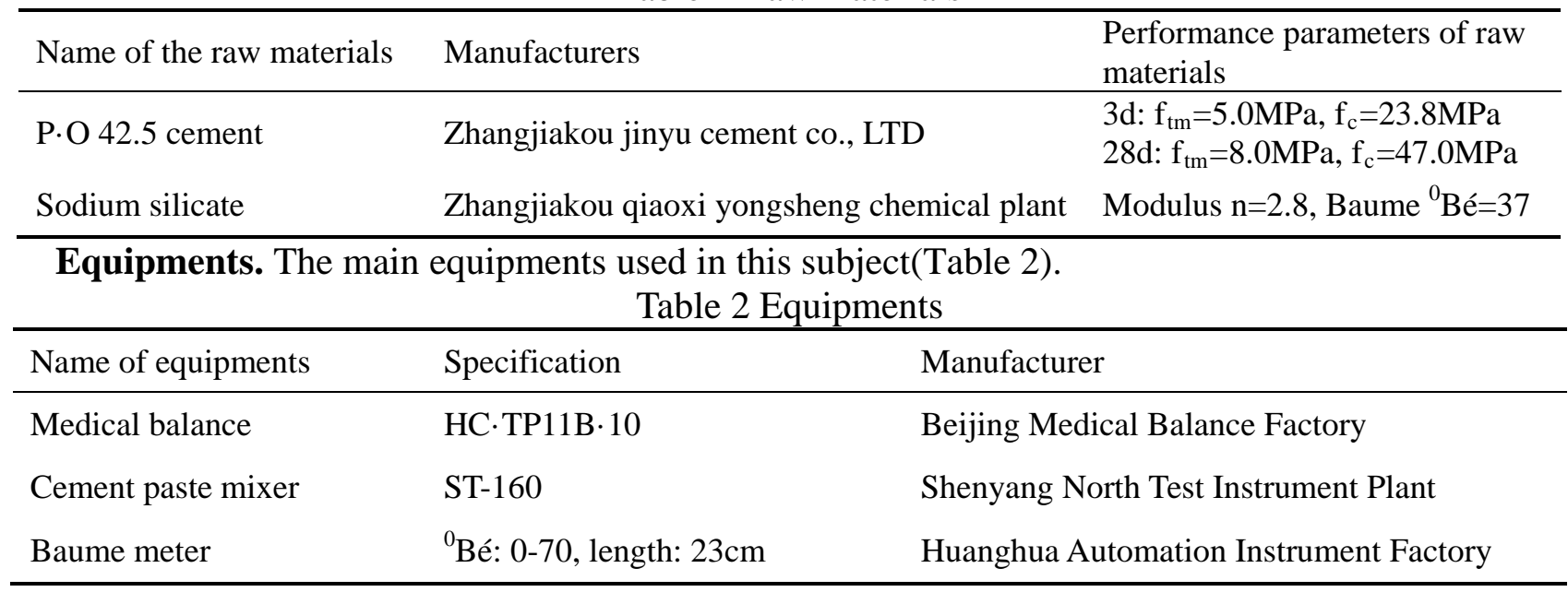

\section{Experimental Research}

Test Scheme. In order to reasonably control the diffusion radius of C-S double liquid grouting slurry material, obtain good grouting plugging effect, and effectively reduce the phenomenon of clogging of pump pipe line, gel time of C-S double solution grouting slurry should be strictly controlled, the gel time is connected with the types of cement, cement slurry consistency (i.e., water cement ratio, W/C), the concentration of Sodium silicate (i.e. Baume ${ }^{0}$ Bé), cement and Sodium 
silicate volume ratio, the types and admixture of additives and admixture and species of admixture and other factors. The subject of experimental research on mixture ratio design: select the P. $\mathrm{O} 42.5$ cement, cement and Sodium silicate volume ratio is $1: 1$, cement slurry W/C is $0.6,0.7,0.8,0.9$, ${ }^{0}$ Bé of Sodium silicate is 21, 25, 29, 33, combine into 16 groups ratios for determination of gel time.

Experimental Data. Mixture ratio designed and gel time tested of C-S double liquid grouting material(Table 3 and table 4).

Table 3 Mixture ratio of double liquid grouting material

\begin{tabular}{|c|c|c|c|c|}
\hline \multirow{2}{*}{$\begin{array}{l}\text { Serial number of } \\
\text { mixture ratio }\end{array}$} & \multirow{2}{*}{ number of mixture ratio } & \multicolumn{2}{|c|}{ Cement slurry(1000ml) } & \multirow{2}{*}{ Sodium silicate(ml) } \\
\hline & & Cement (g) & Water(ml) & \\
\hline H01 & C6V1.0S21+N & 1100 & 660 & 1000 \\
\hline H02 & C6V1.0S25+N & 1100 & 660 & 1000 \\
\hline H03 & C6V1.0S29+N & 1100 & 660 & 1000 \\
\hline H04 & C6V1.0S33+N & 1100 & 660 & 1000 \\
\hline H05 & C7V1.0S21+N & 993 & 695 & 1000 \\
\hline H06 & C7V1.0S25+N & 993 & 695 & 1000 \\
\hline H07 & C7V1.0S29+N & 993 & 695 & 1000 \\
\hline H08 & C7V1.0S33+N & 993 & 695 & 1000 \\
\hline H09 & $\mathrm{C} 8 \mathrm{~V} 1.0 \mathrm{~S} 21+\mathrm{N}$ & 900 & 720 & 1000 \\
\hline H10 & C8V1.0S25+N & 900 & 720 & 1000 \\
\hline H11 & C8V1.0S29+N & 900 & 720 & 1000 \\
\hline H12 & $\mathrm{C} 8 \mathrm{~V} 1.0 \mathrm{~S} 33+\mathrm{N}$ & 900 & 720 & 1000 \\
\hline H13 & C9V1.0S21+N & 850 & 765 & 1000 \\
\hline H14 & C9V1.0S25+N & 850 & 765 & 1000 \\
\hline H15 & C9V1.0S29+N & 850 & 765 & 1000 \\
\hline H16 & $\mathrm{C} 9 \mathrm{~V} 1.0 \mathrm{~S} 33+\mathrm{N}$ & 850 & 765 & 1000 \\
\hline
\end{tabular}

Description: meaning of symbols in the number of mixture ratio in the follow:

C--indicate the cement slurry;

$6,7,8,9$--indicate the cement slurry water cement ratio, that is, $\mathrm{W} / \mathrm{C}$ are $0.6,0.7,0.8,0.9$;

V1.0--indicate the volume of Sodium silicate was 1 time cement slurry;

S--indicate Sodium silicate;

21, 25, 29, 33--indicate the Baume of Sodium silicate, that is ${ }^{0}$ Bé are 21, 25, 29, 33;

$\mathrm{N}$--indicate do not add additive and admixture. 
Table 4 Gel time of double liquid grouting material

\begin{tabular}{|c|c|c|c|c|c|}
\hline $\begin{array}{l}\text { Serial number } \\
\text { of mixture ratio }\end{array}$ & $\begin{array}{l}\text { Number of mixture } \\
\text { ratio }\end{array}$ & $\begin{array}{l}\text { Gelation time } \\
\mathrm{t}(\mathrm{s})\end{array}$ & $\begin{array}{l}\text { Serial number } \\
\text { of mixture }\end{array}$ & $\begin{array}{l}\text { Number of mixture } \\
\text { ratio }\end{array}$ & $\begin{array}{l}\text { Gelation time } \\
\mathrm{t}(\mathrm{s})\end{array}$ \\
\hline H01 & C6V1.0S21+N & 57 & H09 & C8V1.0S21+N & 50 \\
\hline H02 & C6V1.0S25+N & 54 & $\mathrm{H} 10$ & C8V1.0S25+N & 52 \\
\hline H03 & C6V1.0S29+N & 39 & H11 & C8V1.0S29+N & 55 \\
\hline H04 & C6V1.0S33+N & 67 & H12 & $\mathrm{C} 8 \mathrm{~V} 1.0 \mathrm{~S} 33+\mathrm{N}$ & 37 \\
\hline H05 & C7V1.0S21+N & 48 & H13 & C9V1.0S21+N & 57 \\
\hline H06 & C7V1.0S25+N & 47 & H14 & C9V1.0S25+N & 56 \\
\hline H07 & C7V1.0S29+N & 33 & H15 & C9V1.0S29+N & 47 \\
\hline H08 & C7V1.0S33+N & 61 & H16 & C9V1.0S33+N & 57 \\
\hline
\end{tabular}

\section{Data Analysis}

Analysis of Gel Time of C-S Double Liquid Grouting Material. According to data of C-S double liquid grouting material of gel time in table 4, the influence diagram of water cement ratio and the Baume degree of grouting materials on gel time can be respectively made(Fig.1 and Fig.2).

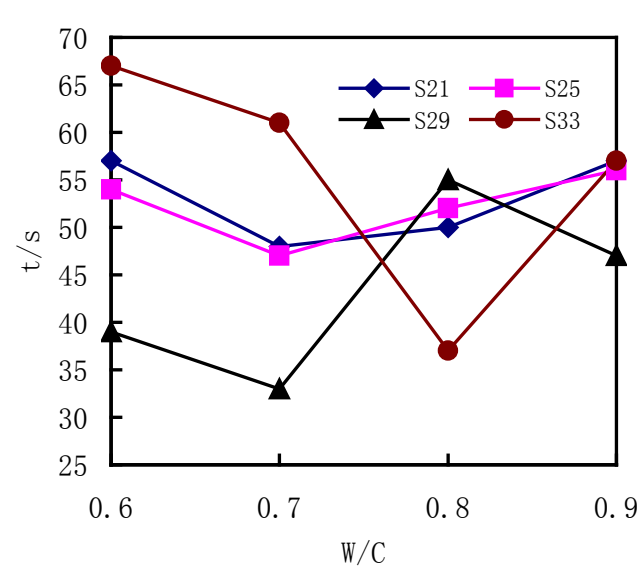

Fig. 1 Influence of W/C on the Gel time with different ${ }^{0} \mathrm{Bé}$

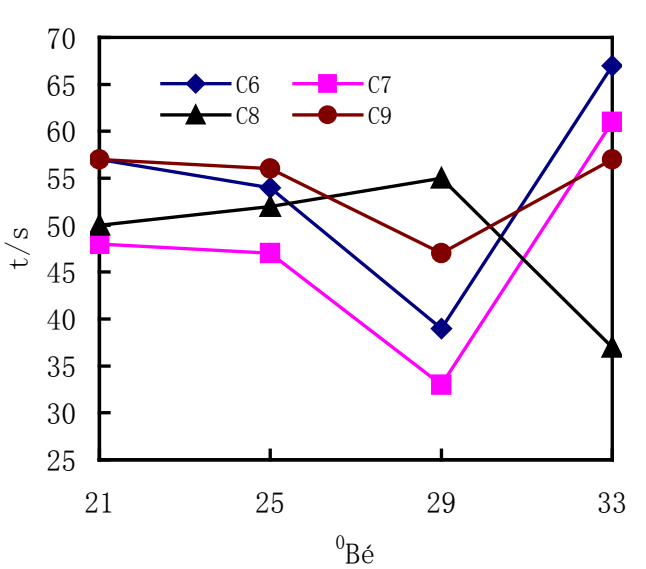

Fig. 2 Influence of ${ }^{0} \mathrm{Bé}$ on the Gel time with different W/C

The analysis from fig.1: when the Sodium silicate slurry of 0Bé are 21 and 25, the gel time of C-S double liquid grouting material along with the increase of cement slurry W/C presents basically stable trend; when the Sodium silicate slurry of ${ }^{0}$ Bé are 29 and 33, the gel time of C-S double liquid grouting material along with the increase of cement slurry W/C, shows the phenomenon of larger change and not obvious change rule, but still in range of requirement of setting time of the double liquid grouting material used in the project.

The analysis from fig.2: when the cement slurry W/C are $0.6,0.7$ and 0.9 , the gel time of C-S double liquid grouting materials with the increase of the Sodium silicate grouting Baume ${ }^{0}$ Bé presents firstly decreasing and then increasing; when the cement slurry $\mathrm{W} / \mathrm{C}$ is 0.8 , the gel time of C-S double liquid grouting material with the increase of the Sodium silicate grouting Baume ${ }^{0}$ Bé presents firstly increasing and then decreasing, that is, when the water cement ratio is 0.8 , the gel time shows the opposite rule.

Analysis of C-S Double Liquid Grouting Material's Technology Economy. The cement has wide source and low price, the high compressive strength of cement stone, good permeability 
performance, simple process and equipment, convenient operation etc.. Sodium silicate slurry is rich in resources, low price, less pollution, good groutability, with many new curing agent, properties of Sodium silicate seriflux have been improved, is a kind of promising slurry. C-S double liquid grouting material in the prerequisite of having cement slurry single liquid grouting material's basic advantages, overcome the single liquid grouting cement slurry gel time is long and not easy to control, low rate of stone; and make the biggest play of cement-Sodium silicate two grouting material, improve the effect of grouting and the quality of the project ; in construction foundation reinforcement, water-glass cement volume ratio is 1:1 for use and can save a large amount of cement, further reduce the cost; besides, in recent years, C-S double liquid grouting technology is constantly improving, perfecting and advancing in engineering practice, so its construction equipments and technology are quite mature.

\section{Conclusion and Prospect}

Based on the measurement and comparative analysis of C-S double liquid grouting material of gel time, can be clearly found: the incorporation of Sodium Silicate in cement slurry can effectively short and control the gel time of grouting material; and low Baume mixed into cement slurry (i.e. ${ }^{0}$ Bé 21 and 25) more easily control the stability of the grouting material than high Baume(i.e. ${ }^{0}$ Bé 29 and 33) Sodium silicate.

Considering the current grouting material's environmental issues, such as shortcomings of poor durability and so on, seek the injectability, strong permeability, cheap price and convenient construction of green new grouting material will be the leading direction of grouting materials in the future.

\section{Acknowledgements}

The experimental study from the Zhangjiakou Municipal Science and Technology Bureau and the seismic research project (1321011B).

\section{References}

[1] JGJ/T 211-2010, Construction of cement-sodium silicate double liquid grouting technical specification [S].

[2] GB 50025-2004, Building standard in collapsible loses plateau[S].

[3] HG/T 20691-2006, Technical regulations of high pressure jet grouting construction operation [S].

[4] X.J. Xue: Brief discussion on treatment of collapsible loess foundation[J]. Chinese western science and technology(2010).

[5] Y. Zhang, Q. Chen: Application of sodium silicate in building materials[J]. Choingqing Building(2012).

[6] Q. Y. Gao, Buidling Materials[M]. The fourth edition, Wuhan: Wuhan University of Technology Press(2012). 